\title{
The Influence of Academic Autonomous Motivation on Learning Engagement and Life Satisfaction in Adolescents: The Mediating Role of Basic Psychological Needs Satisfaction
}

\author{
Yuan Guo ${ }^{1}$ \\ ${ }^{1}$ School of legal studies, Guangdong University of Foreign Studies, Guangzhou, China \\ Correspondence: Yuan Guo, School of legal studies, Guangdong University of Foreign Studies, Guangzhou, \\ Guangdong, China.
}

Received: May 2, 2018 Accepted: May 20, 2018 Online Published: May 23, 2018

doi:10.5539/ijel.v8n5p254 URL: https://doi.org/10.5539/ijel.v8n5p254

\begin{abstract}
A total of 418 adolescents completed the Revised Academic Self-Regulation Questionnaire, the Utrecht Work Engagement Scale-Student, the Basic Needs Satisfaction Scale, and the Satisfaction with Life Scale. Based on self-determination theory, this study examines the relationship between academic autonomous motivation, basic psychological needs satisfaction, learning engagement, and life satisfaction. Results indicate that adolescents' academic autonomous motivation has a significant predictive effect on life satisfaction and learning engagement and that the satisfaction of basic psychological needs plays a mediating role on this predictive effect.
\end{abstract}

Keywords: academic autonomous motivation, learning engagement, life satisfaction, basic psychological needs satisfaction, adolescents

\section{Introduction}

Schaufeli initially extended research on work engagement to the field of student learning by proposing the concept of learning engagement, defined as a positive, fulfilling, stable, persistent, learning-related state of mind (Schaufeli, Salanova, Gonzálezromá, \& Bakker, 2002). This state is based on two dimensions of well-being, motivation and happiness, which contribute to other constructs. For example, burnout is characterized by low levels of motivation and happiness, whereas engagement is marked by high levels of motivation and happiness. Schaufeli also divided learning engagement across three dimensions: vigor, dedication, and absorption. Vigor is characterized by high levels of energy and mental resilience during learning, willingness to invest effort into one's studies, and persistence in the face of challenges. Dedication is characterized by a sense of significance, enthusiasm, inspiration, pride, and challenge. Absorption refers to being fully concentrated on and deeply engrossed in one's studies, such that time passes quickly and an individual may have difficulty detaching him- or herself from studies (Schaufeli, Martínez, Marques Pinto, Salanova, \& Bakker, 2008). Learning engagement is an important predictor of academic achievement as well as an effective indicator of the quality of learning. It has also been shown to exert a profound effect on students' development and growth (Christenson, Reschly, \& Wylie, 2012a). Andrew and Ronald (2009) found that learning engagement can promote students' academic achievement, improve professional maturity, and reduce attrition. Rhodes (2007) discovered that learning engagement is significantly and positively correlated with academic performance. Learning engagement can also enable individuals to maintain a good physical and mental state. Students who devote more effort to their studies tend to exhibit better mental and physical health than those who invest less time (Gao, 2016). Research has revealed that learning engagement mediates the effects of academic work characteristics on students' physical and mental health (Steele \& Fullagar, 2009). Therefore, the factors that influence learning engagement warrant further consideration.

Learning motivation is an important factor shaping learning engagement (Christenson, Reschly, \& Wylie, 2012b) and can directly predict the extent of students' learning engagement (Walker, Greene, \& Mansell, 2006). Self-determination theory (SDT) (Deci \& Ryan, 1985) argues that motivation can be divided into autonomous motivation and controlled motivation according to the degree of self-determination of motivation. Self-motivated motivation, referring to an individual's motivation to complete an activity of his or her own volition, includes internal motivation, integrated motivation, and identified motivation (e.g., interest and personal beliefs). 
Controlled motivation refers to engaging in an activity out of internal pressure (e.g., feelings of guilt) or external pressure (e.g., demands from others) and includes internal and external motivation (Ratelle, Guay, Vallerand, Larose, \& Senecal, 2007; Vansteenkiste \& Sheldon, 2006). Autonomous motivation has been found to be negatively correlated with academic burnout (Reeve, 2013) but significantly positively correlated with learning engagement; it has also been shown to help reduce or prevent study burnout in adolescents (Liu, 2015). By contrast, controlled motivation is positively correlated with study burnout (Vansteenkiste et al., 2005) and negatively correlated with learning engagement (Luo, Zhao, \& Wang, 2014).

SDT holds that humans' basic psychological needs include autonomy, competence, and relatedness (Deci \& Ryan, 2000). Autonomy is a psychological need to determine one's own behavior to a certain extent. Relatedness is the need to acquire a sense of belonging, namely the necessity for care and support from the environment or others. Competence is the need to be effective in one's pursuits and certain activities (Yu et al., 2012). The satisfaction of these three basic needs is the source of individuals' happiness (Deci \& Ryan, 2000). Individual satisfaction is also significantly positively correlated with vitality and positive emotions and negatively correlated with negative emotions and symptoms ( $\mathrm{Li}, 2009)$. The satisfaction of basic psychological needs has been confirmed to influence individuals' learning engagement (Chen \& $\mathrm{Xu}, 2013)$. Academic autonomous motivation promotes the satisfaction of basic psychological needs, and the satisfaction of these needs in students can effectively predict learning-related behavioral outcomes such as learning engagement and academic performance(Jang, Kim, \& Reeve, 2012; Ni \& Wu, 2011). Academic autonomous motivation allows individuals to experience self-control, an enhanced sense of belonging, increased self-efficacy, and improved academic development. Learning engagement following from controlled motivation is neither autonomous nor voluntary; individuals tend to feel controlled and unfulfilled in the three basic psychological needs of autonomy, competence, and relatedness. Hence, it naturally cannot improve individuals' life satisfaction (Chen \& Huang, 2016).The satisfaction of basic psychological needs may be presumed to play a mediating role between academic autonomous motivation and life satisfaction.

No relevant research in China has directly explored the impact of academic autonomous motivation on learning engagement; however, indirect evidence has illuminated this relationship. When adolescents can choose learning material and styles by themselves, they tend to be more invested in learning. These behaviors also have a cross-context migration effect. On the contrary, if a student's school or parents force him or her to be committed to academic studies, the child's freedom of choice and willingness to study independently will be reduced (Ni \& $\mathrm{Wu}, 2011)$. Adolescents with a higher degree of satisfaction of basic psychological needs generally exhibit better learning engagement than other students (Luo, Zhao, \& Wang, 2014). Accordingly, the author infers that academic autonomous motivation can positively predict adolescents' learning engagement and that the satisfaction of basic psychological needs may play a mediating role in this prediction. In summary, this study investigates the influence of academic autonomous motivation on adolescents' life satisfaction and learning engagement and examines the mediating role of satisfaction of basic psychological needs.

\section{Research Method}

\subsection{Participants}

To explore the research objectives, 460 questionnaires were collected from two middle schools in Guangdong Province. Of these, 42 were invalid with either no answers or answers with a clear pattern in total, 418 valid questionnaires were retained for analysis (216 boys, 202 girls; $M=15.69, S D=0.86$ ).

\subsection{Measures}

\subsubsection{Academic Self-Regulation Questionnaire}

Academic autonomous motivation was measured using the Academic Self-Regulation Questionnaire, Standard Edition (SRQ-A), which is tailored to students from primary school (beginning in second grade) to secondary school. Zhang, Liu, Shi, and Fu (2011) conducted confirmatory factor analysis (CFA) with the questionnaire and found the various fitting indices to be good; Cronbach's alpha of each subscale was $0.81,0.81,0.73$, and 0.80 , respectively. The questionnaire includes 32 items addressing four dimensions: external adjustment (nine questions), introjected adjustment (nine questions), identity adjustment (seven questions), and intrinsic motivation (including integration adjustment; seven questions). The SRQ-A was used in this study to measure the degree of internalization of learning motivation. External adjustment indicates that students' motivation for learning is compelled by external pressures to obtain rewards or avoid punishment. Introjected adjustment suggests that students' learning motivation begins to shift from external to internal as they learn (e.g., to earn praise or avoid feelings of guilt and shame). Identity adjustment suggests that students internalize external requirements into their own values and learn while recognizing the meaning and importance of learning. 
Intrinsic motivation implies that students learn completely out of their own interest.

SDT captures external and introjected adjustment as controlled motivation, identity adjustment, integration adjustment, and internal motivation as autonomous motivation. Because integration adjustment is quite similar to intrinsic motivation, integration adjustment was not measured separately but instead evaluated along with intrinsic motivation in the questionnaire. In this study, controlled motivation was calculated based on the mean of external and introjected adjustment, and autonomous motivation was calculated by the mean of identity adjustment and internal motivation (Grolnick \& Ryan, 1989; Luo, Zhao, \& Wang, 2014). Items were scored on a 4-point Likert-type scale $(1=$ not meet at all, $4=$ full compliance $)$. In this study, Cronbach's alpha was 0.87 , and the coefficients of each subscale were as follows: 0.70 (external adjustment), 0.76 (introjected adjustment), 0.82 (identity adjustment), and 0.81 (intrinsic motivation). Thus, reliability was acceptable to good for all scales.

\subsubsection{The Utrecht Work Engagement Scale-Student}

The Chinese version of the Utrecht Work Engagement Scale-Student (UWES-S) used in this study was revised by Fang et al. (2008) according to Schaufeli's student edition of the UWES. The scale includes 17 questions encompassing three dimensions: vigor, dedication, and absorption. Items are scored on a 7-point Likert-type scale $(1=$ never before, $7=$ always $)$. Higher scores imply stronger learning engagement. CFA identified the following fit indices: $\chi^{2} / d f=2.016$, RMSEA $=0.064, \mathrm{NFI}=0.929, \mathrm{TLI}=0.926, \mathrm{CFI}=0.962$. Cronbach's alpha for the entire scale was 0.89 , and the alpha coefficients of each subscale were between $0.81-0.94$, implying good to excellent reliability.

\subsubsection{Basic Need Satisfaction Scale}

The Basic Need Satisfaction Scale, organized by Deci and Ryan (2000), contains 21 questions on three dimensions: autonomy need (seven questions), competence need (six questions), and relatedness need (eight questions). Similar to the UWES-S, items are scored on a 7-point Likert-type scale ( 1 = completely disagree, $7=$ completely agree). Autonomy need is used to measure students' ability to act according to their own wishes, including statements such as "In the classroom, I usually can express my own ideas and opinions freely." Competence need measures students' assessment of their own abilities, such as "Most of the time, I can experience a sense of accomplishment from what I do." Relatedness need evaluates students' perceptions of interpersonal relationships, such as "I like the teachers and classmates around me." Higher scores suggest greater satisfaction of basic psychological needs. The scale has reportedly good reliability and structural validity (Liu, Ji, $\&$ Wang, 2012; Yu et al., 2012). The total Cronbach's alpha was 0.85 , and the alpha coefficients of each subscale were $0.76,0.74$, and 0.77 .

\subsubsection{Life Satisfaction Scale}

Pavot and Diener's (2009) Life Satisfaction Scale includes five items scored on a 7-point Likert-type scale (1= strongly disagree, $7=$ strongly agree $)$ with higher scores indicating higher life satisfaction $(\alpha=0.86)$.

To guarantee equivalence between the Chinese and English versions of the four aforementioned scales, the author invited a doctoral student and two post-graduate master's students majoring in psychology to translate each scale into Chinese per Brislin's (1980) recommendation. Potentially unclear items were revised following discussion and confirmation of accurately translated Chinese expressions. Next, Two Chinese-English bilingual teachers who majored in psychology translated the Chinese questionnaire back into English. Finally, two experts were invited to compare the back-translated scales with the original versions to ensure clarity and understanding.

\subsection{Research Procedure and Statistical Analysis}

Prior to conducting the formal study, the researcher explained the purpose and significance of the study to the school. The school reviewed the research questionnaires. After receiving school consent, the researcher introduced the study to adolescents and asked them to consult with their parents before deciding to participate. The researcher and five trained post-graduate master's students majoring in psychology carried out the assessment.

First, the research team provided participants with instructions about the assessment. Participants were given approximately 25 minutes to complete the questionnaire. After that, participants were given a token of thanks for their participation. Considering that self-report instruments may demonstrate common method bias effects, the research team controlled for errors through the following measures as suggested by Zhou and Long (2004). (1) Testing was anonymous; questionnaires were distributed and recovered in the order of seats during the test, and questionnaires were then numbered upon completion. Names were not collected to protect participants' anonymity. (2) The scoring method was modified for different questionnaires (e.g., questions were presented in a different order across tests.). (3) Some questions used reversed scoring. 
SPSS version 21.0 and Mplus 7.0 were used for data analysis and processing. The bootstrapping method was used to test the mediation effect through repeated random sampling $(n=1000)$. Samples were extracted from the original data, from which 1000 medial effect values were generated and stored to form an approximate sampling distribution and calculate the average path coefficients of the mediating effect. If $95 \%$ of the confidence interval (CI) of the average path coefficients did not include 0 , then the mediating effect was considered significant (Preacher \& Hayes, 2008).

\section{Results}

As shown in Table 1, adolescents' academic autonomous motivation was found to be positively correlated with basic psychological needs satisfaction, life satisfaction, and learning engagement. Basic psychological needs satisfaction was also significantly positively correlated with life satisfaction and learning engagement.

Table 1. Descriptive statistics for each variable and correlations among variables

\begin{tabular}{|c|c|c|c|c|c|}
\hline Variable & $M(S D)$ & 1 & 2 & 3 & 4 \\
\hline $\begin{array}{l}1 \text { Academic autonomous } \\
\text { motivation }\end{array}$ & $-2.958(1.25)$ & - & & & \\
\hline $\begin{array}{l}2 \text { Basic psychological needs } \\
\text { satisfaction }\end{array}$ & $4.685(0.73)$ & $0.22 * *$ & - & & \\
\hline 3 Life satisfaction & $0.061(2.15)$ & $0.21 * *$ & $0.54 * *$ & - & \\
\hline 4 Learning engagement & $4.869(0.74)$ & $0.18^{*}$ & $0.49 * *$ & $0.34 * *$ & - \\
\hline
\end{tabular}

Note. ${ }^{*} p<0.05,{ }^{* *} p<0.01,{ }^{* * *} p<0.001$.

Controlling for gender and age, the mediation model was tested using academic autonomous motivation as the independent variable, basic psychological needs satisfaction as the mediating variable, and life satisfaction and learning engagement as the dependent variables. As shown in Table 1, academic autonomous motivation significantly predicted basic psychological needs satisfaction $(\beta=0.22, p<0.001)$, and basic psychological needs satisfaction significantly predicted life satisfaction $(\beta=0.31, p<0.001)$ and learning engagement $(\beta=$ $0.28, p<0.001)$. Basic psychological needs satisfaction significantly mediated the effects of academic autonomous motivation on life satisfaction (mediating effect $=0.07, \mathrm{SE}=0.02, p<0.01,95 \% \mathrm{CI}=[0.03,0.12]$ ) and learning engagement (mediating effect $=0.07, \mathrm{SE}=0.02, p<0.01,95 \% \mathrm{CI}=[0.02,0.11]$ ). When basic psychological needs satisfaction was included in the mediation model, the effect of academic autonomous motivation on life satisfaction declined (from $\beta=0.16, p<0.001$ to $\beta=0.09, p<0.05$ ), as did the effect of academic autonomous motivation on learning engagement ( $f r o m \beta=0.15, p<0.001$ to $\beta=0.08, p<0.05$ ).

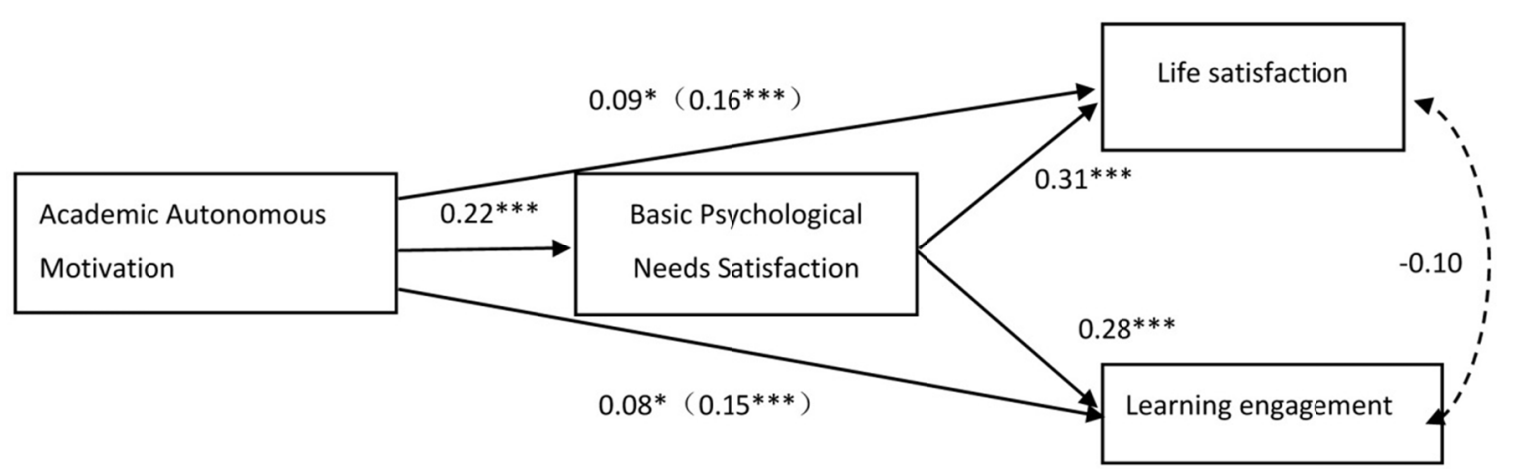

Figure 1. Mediating role of basic psychological needs satisfaction on the effect of academic autonomous motivation on life satisfaction and learning engagement

Note. A one-way arrow represents a predictive effect among variables. Values in parentheses represent the total effect of the predictor variable on the outcome variable; values outside the parentheses represent the direct effect of the predictor variable on the outcome variable after the mediator variable is included. A two-way dashed arrow indicates the correlations of the residuals of the two dependent variables (well-being and prosocial behavior) that are not explained by the predictor and mediator variables. A full line indicates the coefficient is significant; a dotted line indicates it is not. Control variables are not presented in the model diagram for simplicity. 
These results validate the research hypothesis that academic autonomous motivation significantly predicts adolescents' life satisfaction and learning engagement and that basic psychological needs satisfaction significantly mediates the effects of academic autonomous motivation on life satisfaction and learning engagement.

\section{Discussion}

\subsection{Influence of Academic Autonomous Motivation on Adolescents'Life Satisfaction}

This study used a questionnaire to evaluate the positive predictive effect of academic autonomous motivation on adolescents' life satisfaction. Results reveal that basic psychological needs satisfaction mediates this relationship; stronger self-motivation leads to greater autonomy and freedom in learning and better academic development. Similarly, a greater sense of competence, value, and belonging enhances adolescents' life satisfaction. By contrast, learning engagement resulting from controlled motivation does not appear conducive to students' satisfaction of autonomy, competence, and relatedness needs and thus cannot effectively improve life satisfaction.

Learning engagement has also been found to be "self-enhancing" for adolescents (i.e., meeting their own needs and gaining positive experiences; Zhang, 2015). From an SDT perspective, these findings clarify the distinct effects of various academic motivations on adolescents' self-enhancement. Research has shown that learning engagement is a pertinent way for adolescents to improve their life satisfaction (Huang \& Zhuang, 2016); however, this study implied that learning engagement has a conditional limit on the improvement of life satisfaction. Whether learning engagement is motivated by self-motivation is an important determinant of improved life satisfaction. Academic autonomous motivation can satisfy adolescents' basic psychological needs, encourage academic development, enhance their sense of self-worth, and promote harmonious interpersonal relationships; therefore, academic autonomous motivation can improve their life satisfaction more effectively. Academic autonomous motivation also engenders positive adaptation, helping adolescents to understand and internalize the connotation of independent development. On the contrary, academic controlled motivation is derived from perceived internal and external pressures. The satisfaction of basic psychological needs is lower than with academic autonomous motivation, leading to comparatively lower life satisfaction.

\subsection{Influence of Academic Autonomous Motivation on Adolescents' Learning Investment}

This study identified significant positive correlations between learning engagement and three basic psychological needs. Higher levels of satisfaction for these three basic psychological needs lead to lower learning burnout and a greater degree of learning engagement. These findings align with previous research (Sun \& Zhang, 2012). Result also demonstrates significant positive correlations between self-motivation and the three factors of learning engagement. A higher level of self-determination in motivation (i.e., when adolescents are interested in learning or understanding the importance of learning for themselves) promotes enhanced learning engagement and a lower level of learning burnout. By contrast, when learning motivation is controlled (i.e., when motivation results from external pressure or incentives), learning engagement is reduced significantly. Therefore, perhaps self-motivation is the key to stimulating and maintaining learning-related behavior.

These findings support the promotion of academic autonomous motivation on adolescents' learning engagement and underscore basic psychological needs satisfaction as a potential driver behind this promotion. Stronger academic autonomous motivation leads to greater satisfaction of basic psychological needs and a higher degree of learning engagement among adolescents, whereas academic controlled motivation can neither effectively satisfy adolescents' basic psychological needs nor promote learning engagement. The basic psychological need facet of SDT asserts that individuals' degree of internalization of external requirements, values, and rules relies to a great extent on the satisfaction of basic psychological needs during activities, which is largely self-determined and offers individuals a strong sense of satisfaction. A supportive atmosphere has also been shown to inspire self-motivation along with positive behaviors (Connell \& Wellborn, 1991), a greater sense of accomplishment (Miserandino, 1996), and less learning burnout or school attrition (Vallerand \& Bissonnette, 1992). Therefore, as adolescents grow up, it is important for society, schools, and parents to create an autonomous and supportive environment, encourage adolescents to think and solve problems independently, provide them freedom of choice, and promote the formation and development of self-motivation.

\subsection{Promoting Adolescents' Mental Health and Cultivating Learning Engagement}

The results of this study highlight the importance of promoting adolescents' mental health and cultivating learning engagement. Educators should adopt encouraging methods to help adolescents develop autonomous learning habits, encourage them to learn independently, and provide positive experiences rather than coercing 
them to engage in learning activities. Educators should also aim to let adolescents develop their own learning plans and implementation, guide them in reflecting on their plans and making corresponding adjustments, and participate in post-activity evaluation to help students improve their autonomy and life satisfaction. The organic integration component of SDT holds that an environment that supports and satisfies the three basic psychological needs of autonomy, competence, and relatedness (especially autonomy) promotes self-motivation, which further influences cognition and behavior (Deci, Vallerand, Pelletier, \& Ryan, 1991). In the process of cultivating self-directed learning in adolescents, teachers should strive to present a supportive environment in which students feel independently supported. Adolescents' sense of belonging to the school can thus be enhanced along with their perceived learning competence and autonomy. The satisfaction of autonomy, competence, and relatedness ultimately indicates to adolescents that their learning behavior is self-determined, thereby enhancing their self-motivation around learning, increasing learning engagement, and reducing burnout. The motivation adjustment model proposed by Jang et al. (2009) also suggests that a supportive environment promotes the satisfaction of adolescents' basic psychological needs, thus inspiring self-motivation and effectively predicting their degree of learning engagement. Learning engagement in turn predicts behavioral outcomes related to learning, such as academic performance, burnout, and so on.

\subsection{Research Limitations and Prospects}

Despite its revelations, this study has several limitations. First, participants were middle school students in Guangzhou, which limits the generalizability of the results. Subsequent studies should employ samples from other regions and age groups. Second, self-report instruments are often subject to bias. Future work may combine other people's evaluations (e.g., from parents and teachers), behavioral observations, academic records, and other objective reports to ensure a more objective assessment of these constructs while minimizing the social desirability effect. Finally, although this study revealed a mediating effect of the satisfaction of basic psychological needs on life satisfaction and learning engagement, this study was cross-sectional in nature; longitudinal research should be considered to extend the current results.

\section{Conclusion}

(1) The adolescents' academic autonomous motivation is positively correlated with satisfaction of basic psychological needs, life satisfaction, and learning engagement. Basic psychological needs satisfaction also exhibits significant positive correlations with life satisfaction and learning engagement, respectively.

(2) The effect of academic autonomous motivation on life satisfaction and learning engagement is indirectly achieved through the satisfaction of basic psychological needs; that is, basic psychological needs mediate the effect of academic autonomous motivation on life satisfaction and learning engagement.

\section{Acknowledgments}

This paper is supported by National Education Science of China "the 13th Five-year Plan" 2016 Program (EBA160407): Research on the Formation Mechanism of Prosocial Behaviors of College Students---An Example from Undergraduate Volunteers.

\section{References}

Brislin, R. W. (1980). Translation and content analysis of oral and written material. Methodology, 389-444.

Chen, Y. Z., \& Xu, P. P. (2013). Investigating the investment in promoting the study of college students: A perspective of learning psychology based on professional commitment. China Higher Education Research, 9, 94-98.

Chen, Y., \& Huang, S. J. (2016). The relationship between teacher autonomous support and high school students' self-motivation and basic psychological needs. Journal of Southwest China Normal University (Natural Science Edition), 41(10), 141-145.

Christenson, S. L., Reschly, A. L., \& Wylie, C. (2012b). A self-determination theory perspective on student engagement. New York: Springer US.

Christenson. S. L., Reschly, A. L., \& Wylie. C. (2012a). Achievement goal theory, conceptualization of ability/intelligence, and classroom climate. In E. M. Anderman \& H. Patrick (Eds.), Handbook of research on student engagement (pp. 173-192). New York: Springer US. https://doi.org/10.1007/978-1-4614-2018-7

Connell, J. P., \& Wellborn, J. G. (1991). Competence, autonomy, and relatedness: a motivational analysis of self-system processes. Journal of Personality \& Social Psychology, 65, 43-77.

Deci, E. L., \& Ryan, R. M. (2000). The "what" and "why" of goal pursuits: human needs and the 
self-determination of behavior. Psychological Inquiry, 11(4), 227-268. https://doi.org/10.1207/S15327965PLI1104_01

Deci, E. L., Vallerand, R. J., Pelletier, L. G., \& Ryan, R. M. (1991). Motivation and education: The self-determination perspective. Educational Psychologist, $26(3-4), \quad 325-346$. https://doi.org/10.1080/00461520.1991.9653137

Fang, L. T., Shi, K., \& Zhang, F. H. (2008). Study on reliability and validity of the Chinese version of the study input scale. Chinese Journal of Clinical Psychology, 16(6), 618-620.

Gao, J. (2016). The relationship between external motivation and e-learning engagement: from the perspective of self-determination theory. Research on e-education, 10, 64-69.

Grolnick, W. S., \& Ryan, R. M. (1989). Parent styles associated with children's self-regulation and competence in school. Journal of Educational Psychology, 81(2), 143-154. https://doi.org/10.1037/0022-0663.81.2.143

Huang, Z. D., \& Zhuang, Y. (2016). Research on the relationship between the current situation of college students' learning investment and life satisfaction. Continuing Education Research, 10, 123-126.

Jang, H., Kim, E. J., \& Reeve, J. (2012). Longitudinal test of self-determination theory's motivation mediation model in a naturally occurring classroom context. Journal of Educational Psychology, 104(4), 1175-1188. https://doi.org/10.1037/a0028089

Jang, H., Reeve, J., Ryan, R. M., \& Kim, A. (2009). Can self-determination theory explain what underlies the productive, satisfying learning experiences of collectivistically oriented Korean students? Journal of Educational Psychology, 101(3), 644-661. https://doi.org/10.1037/a0014241

$\mathrm{Li}$, Q. H. (2009). The relationship between the satisfaction of basic psychological needs and the sense of well-being of high school students (Doctoral dissertation, Hebei Normal University).

Liu, B. Y. (2015). The development of self-determination motivation of junior high school students and its impact on academic investment-The mediating role of achievement goals (Doctoral dissertation, Hebei Normal University).

Liu, H. J., Ji, H. Y., \& Wang, Y. (2012). Basic psychological needs satisfaction the prediction of job burnout and work commitment of doctors. Journal of Hebei University (Philosophy \& Social Sciences Edition), 37(2), 93-99.

Luo, Y., Zhao, M., \& Wang, Z. H. (2014). The effect of junior high school students' perception of teacher autonomy support on academic burnout: The mediating role of basic psychological needs and autonomous motivation. Psychological Development and Education, 30(3), 312-321.

Miserandino, M. (1996). Children who do well in school: Individual differences in perceived competence and autonomy in above-average children. Journal of Educational Psychology, 88(88), 203-214. https://doi.org/10.1037/0022-0663.88.2.203

Ni, Sh. G., \& Wu, X. C. (2011). Learning engagement: Concepts, measurements, and related variables. Psychological Research, 4(1), 81-87.

Pavot, W., \& Diener, E. (2009). Review of the Satisfaction With Life Scale. Assessing Well-Being. Springer Netherlands. https://doi.org/10.1007/978-90-481-2354-4_5

Preacher, K. J., \& Hayes, A. F. (2008). Asymptotic and resampling strategies for assessing and comparing indirect effects in multiple mediator models. Behavior Research Methods, 40(3), 879-891. https://doi.org/10.3758/BRM.40.3.879

Ratelle, C. F., Guay, F., Vallerand, R. J., Larose, S., \& Senécal, C. (2007). Autonomous, controlled, and amotivated types of academic motivation: A person-oriented analysis. Journal of Educational Psychology, 99(4), 734-746. https://doi.org/10.1037/0022-0663.99.4.734

Rhodes, H. (2007). Confronting the challenges of student engagement: A case study of a school-based intervention (Doctoral dissertation, RAND).

Ryan, R. M., \& Connel, J. P. (1989). Perceived locus of causality and internalization: examining reasons for acting in two domains. Journal of Personality \& Social Psychology, 57(5), 749-761. https://doi.org/10.1037/0022-3514.57.5.749

Schaufeli, W. B., Martínez, I. M., Marques Pinto, A., Salanova, M., \& Bakker, A. B. (2008). Burnout and engagement in university students: A cross-national study. Journal of Cross-Cultural Psychology, 33(33), 
464-481.

Schaufeli, W. B., Salanova, M., Gonzálezromá, V., \& Bakker, A. B. (2002). The measurement of engagement and burnout: A two sample confirmatory factor analytic approach. Journal of Happiness Studies, 3(1), 71-92. https://doi.org/10.1023/A:1015630930326

Steele, J. P., \& Fullagar, C. J. (2009). Facilitators and outcomes of student engagement in a college setting. The Journal of Psychology, 143(1), 5-27. https://doi.org/10.3200/JRLP.143.1.5-27

Sun, G. X., \& Zhang, L. W. (2012). Basic psychological needs and athletes' psychological fatigue: A self-determination theory perspective. Journal of Tianjin Sports University, 27(2), 126-132.

Vallerand, R. J., \& Bissonnette, R. (1992). Intrinsic, extrinsic, and amotivational styles as predictors of behavior: A prospective study. Journal of Personality, https://doi.org/10.1111/j.1467-6494.1992.tb00922.x

Vansteenkiste, M., \& Sheldon, K. M. (2006). There's nothing more practical than a good theory: Integrating motivational interviewing and self-determination theory. British Journal of Clinical Psychology, 45(1), 6382. https://doi.org/10.1348/014466505X34192

Vansteenkiste, M., Zhou, M., Lens, W., \& Soenens, B. (2005). Experiences of autonomy and control among Chinese learners: Vitalizing or immobilizing? Journal of Educational Psychology, 97(3), 468-483. https://doi.org/10.1037/0022-0663.97.3.468

Walker, C. O., Greene, B. A., \& Mansell, R. A. (2006). Identification with academics, intrinsic/extrinsic motivation, and self-efficacy as predictors of cognitive engagement. Learning \& Individual Differences, 16(1), 1-12. https://doi.org/10.1016/j.lindif.2005.06.004

Wefald, A. J., \& Downey, R. G. (2009). Construct dimensionality of engagement and its relation with satisfaction. Journal of Psychology, 143(1), 91-111. https://doi.org/10.3200/JRLP.143.1.91-112

Yu, CH. F., Zhang, W., Zeng, Y. Y., Ye, T., Hu, J. P., \& Li, D. L. (2012). The relationship between teenage gratitude, basic psychological needs and pathological network use. Psychological Development and Education, 28(1), 83-90.

Zhang, J. H., Liu, G. R., Shi, X., \& Fu, X. J. (2011). The relationship between motivating motivation and pupils' creative thinking: the mediating role of autonomy motivation. Chinese Journal of Psychology, 43(10), $1138-1150$.

Zhang, X. Y. (2015). Research on the influence of social support on college students' learning engagement-based on the mediating role of professional commitment. Education Development Research, 9, 59-64.

Zhou, H., \& Long, L. R. (2004). Statistical tests and control methods for common method bias. Advances in Psychological Science, 12(6), 942-950.

\section{Copyrights}

Copyright for this article is retained by the author, with first publication rights granted to the journal.

This is an open-access article distributed under the terms and conditions of the Creative Commons Attribution license (http://creativecommons.org/licenses/by/4.0/). 